\title{
Hyperbaric Oxygen for a Thalassaemic Leg Ulcer
}

\section{Sqn Ldr M N Richmond,}

MB, ChB, FFARCS, Senior Specialist in Anaesthetics

Major K A Galbraith,

MB, ChB, FRCS, Senior Specialist in Surgery

\section{Wg Cdr J T G Rogerson, MB, ChB, FFARCS, Consultant in Anaesthetics}

The Princess Mary's Royal Air Force Hospital, RAF Akrotiri, BFPO 57

SUMMARY: A thalassaemic ulcer in a male Greek Cypriot patient, resistant to standard medical treatment, was treated using hyperbaric oxygen in a recompression chamber. The patient breathed $100 \%$ oxygen by face mask whilst the chamber was compressed with air to a pressure of 2.5 atmospheres absolute. The ulcer became fully epithelialised within three weeks of starting treatment.

\section{Introduction}

Thalassaemias are characterized by an imbalance in the production of globin polypeptide chains due to the absence or reduced expression of one or more of the globin genes, and occur particularly frequently in the Mediterranean area. Leg ulcers have been described in both alpha ${ }^{1}$ and beta thalassaemia ${ }^{2}$.

We report a patient with thalassaemia intermedia in whom treatment of a leg ulcer was effected by use of hyperbaric oxygen in a recompression chamber.

\section{Case Report}

A fit, 24 year old Greek Cypriot male was admitted to hospital with a three month history of an ulcer above his right ankle, resistant to standard medical treatment.

His past history revealed that he had thalassaemia but had declined treatment. There was a known significant family history of thalassaemia (see family tree). Examination showed a $4 \mathrm{~cm}$ indurated and pigmented area with a central $2 \mathrm{~cm}$ ulcer with no rolled edge, just above the right medial malleolus. No varicose veins could be demonstrated in either leg. The heart and lungs were normal and the spleen was not palpable.

Haematological investigations: $\mathrm{Hb} 7.8 \mathrm{~g} / \mathrm{dl}, \mathrm{PCV}$ 0.26 , MCV $48 \mathrm{fl}, \mathrm{MCH} 14 \mathrm{pg}$. MCHC $30 \mathrm{~g} / \mathrm{dl}$, WBC 10.8 $\times 10^{9} / 1$; reticulocytes $15 \%$. In the blood film the red cells showed marked anisocytosis and poikilocytosis. Initial haemoglobin electrophoresis was reported as follows: $\mathrm{HbA}_{2} 9 \%, \mathrm{HbF} 26 \%$. HbH negative and $\mathrm{HbS}$ negative. More detailed studies on another occasion showed $\mathrm{HbA}_{2} 8.8 \%, \mathrm{HbF} 29.1 \%, \propto / 3$ ratio 4.484 and $\propto /$ non $\propto$ 3.279. The haematological diagnosis was considered to be thalassaemia intermedia, probable genotype $\propto_{1} \beta B$, the patient being homozygous for the $B$ thalassaemic gene and heterozygous for the $\propto$ gene.

Venography revealed a normal venous system.

A course of hyperbaric oxygen in our recompression chamber, for treatment of his thalassaemic ulcer, was commenced. The recompression chamber used was a
CLUCAS 6 man, twin compartment model. The chamber was compressed with air to a pressure of $2.5 \vec{\omega}$ atmospheres absolute. The duration of each session was 90 minutes at depth and throughout the patient breathed $100 \% \mathrm{O}_{2}$, by face mask ${ }^{3}$. After 14 'sessions' over 3 week the ulcer was fully epithelialised. One year later the 응 patient has an area of pigmented good quality skin at the site of the healed ulcer with no induration, tenderness $\partial$ pain.

\section{Discussion}

Leg ulcers are most commonly due to venots insufficiency ${ }^{4}$ and are usually located in the area of the medial malleolus close to the medial perforators. L ulcers associated with thalassaemia are relatively rare: they also develop in the area of the medial malleolus ${ }^{2}$. potential for misdiagnosis of the aetiology of leg ulceration exists, especially in patients of Mediterranean origin. Differentiation between a venous and thalassaemic ulcer can be aided by venography.

The events leading to thalassaemic ulceration are not well established. They tend to occur in young adulthood, often develop after minor trauma, are characteristically slow to heal and are prone to recur. The severity is not apparently related to the severity of anaemia, degree of haemosiderosis or the patient's transfusion requirements ${ }^{2}$. The mechanism may be that indeformable and $\overrightarrow{\widetilde{D}}$ rigid thalassaemic red blood cells cause venous stasis, venous hypertension and impaired blood flow through capillary beds ${ }^{5}$. A contributing factor ${ }^{2}$ may be impaired tissue oxygenation resulting from the high affinity the thalassaemic fetal $\mathrm{Hb}$ has for oxygen. A correlation between the percentage of fetal haemoglobin and the severity of thalassaemic ulcers has been described ${ }^{2}$.

Hyperbaric oxygen causes more oxygen to dissolve in $\frac{D}{0}$ the superficial tissue of the ulcer which enhances healing by stimulating fibroblastic activity and collagen $N$ production. It also facilitates fibroblastic proliferation $N$ which promotes capillary budding ${ }^{3}$. 
Patient's Family Tree

Patient described is III 6
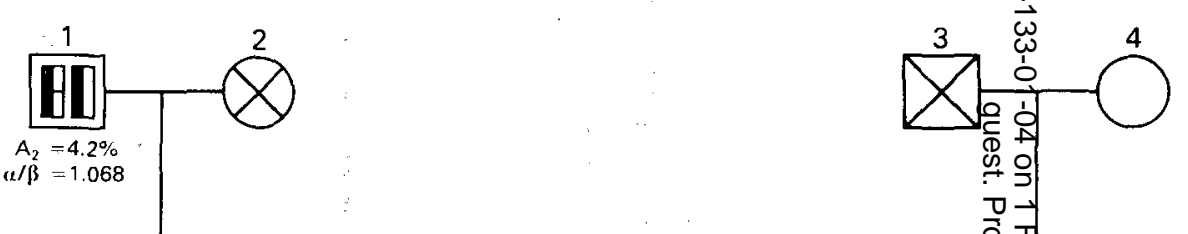

II
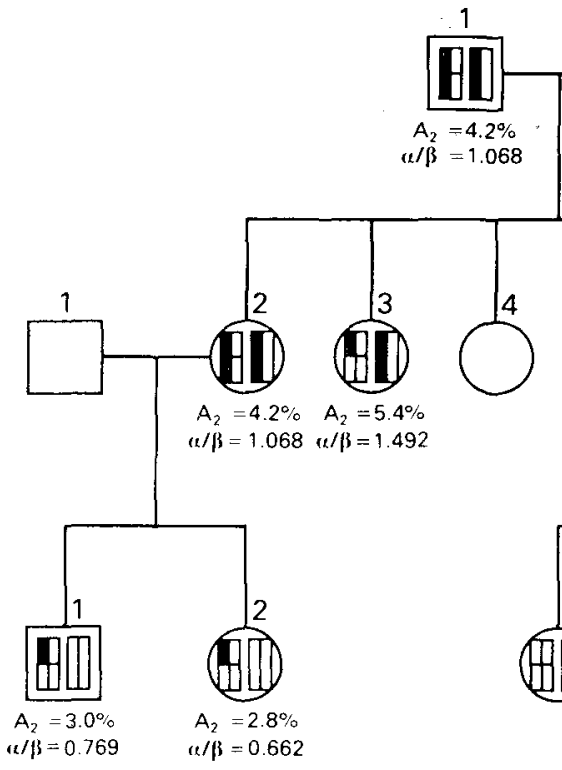

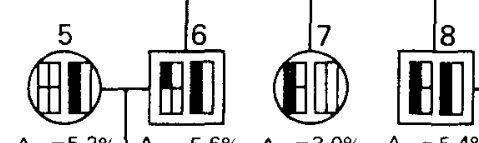

$A_{2}=5.2 \% \quad A_{2}=5.6 \% \quad A_{2}=3.0 \% \quad A_{2}=5.4 \%$ $\alpha / \beta=2.15 \quad \alpha / \beta=1.447 \quad \alpha / \beta=0.559 \quad \alpha / \beta=1.16$

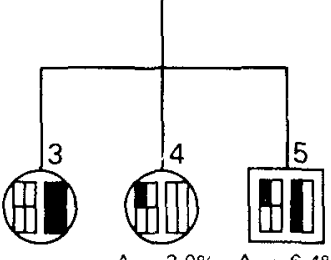

$A_{2}=3.0 \% \quad A_{2}=6.4 \%$ $\alpha / \boldsymbol{\beta}=0.706 \quad \alpha / \beta=1.453$

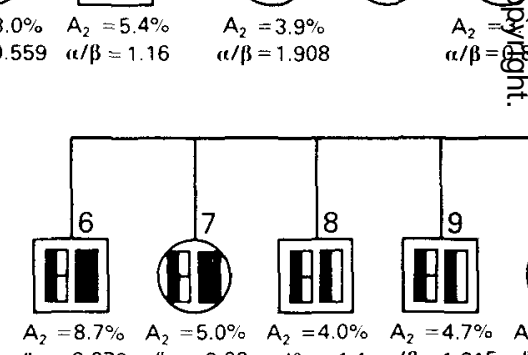

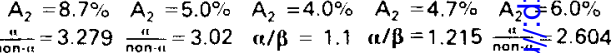

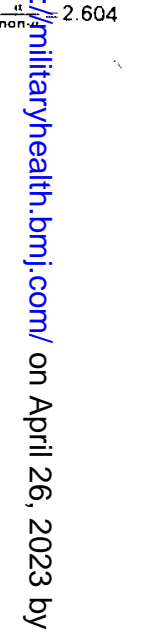

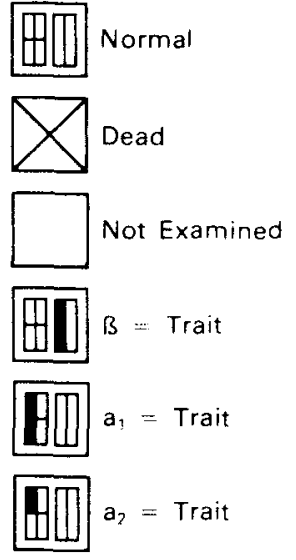


A local hermetic chamber enclosing the limb with oxygen supplied locally at a pressure not exceeding 22 $\mathrm{mmHg}$ above atmospheric pressure has been used to aid the healing of ulcers of many aetiologies ${ }^{6}$. Greater pressures applied locally cause problems of venous stasis and obstruction of capillary blood flow ${ }^{6}$. Local chambers are expensive, require sterilisation and may cause cross infection if shared by several patients ${ }^{7}$. Strong disposable polythene bags have been used to apply local hyperbaric oxygen to limbs ${ }^{7}$. These are cheap, require no sterilisation and are capable of maintaining the required pressure. Using local hyperbaric oxygen it has been shown $^{8}$ that a very high gradient of oxygen saturation exists between the surface and deeper layers of granulation tissue. Patients with poor blood supply to the deeper layers of the ulcer would probably benefit from treatment in a hyperbaric oxygen chamber.

The benefits of systemic hyperbaric therapy follow from its effect on the absorption and transport of oxygen.

\begin{tabular}{cccc}
\hline $\begin{array}{c}\text { Ambient } \\
\text { Pressure }\end{array}$ & $\mathbf{\% O}_{2}$ & $\begin{array}{c}\text { Arterial pO } \\
\text { (approx.) } \\
\mathbf{~ P ~ P a ~}\end{array}$ & $\begin{array}{c}\mathbf{O}_{2} \text { in simple } \\
\text { solution } \\
\mathbf{m l} / \mathbf{1 0 0 m l} \text { Plasma }\end{array}$ \\
101.3 & 20.9 & 13.5 & 0.3 \\
101.3 & 100 & 80 & 1.8 \\
202.6 & 100 & 186 & 4.2 \\
303.9 & 100 & 268 & 6.0 \\
\hline
\end{tabular}

The higher the $\mathrm{pO}_{2}$ of the inspired gas the higher the arterial $\mathrm{pO}_{2}$ in an almost linear fashion.

Although oxygen stores are considerably increased when hyperbaric oxygen is given tissue, oxygen is not necessarily commensurate with arterial $\mathrm{pO}_{2}$. This depends on many factors including the properties of haemoglobin, cardiac output, regional tissue perfusion and upon the diffusion of oxygen from capillaries into the tissues.
We can find no reports in the literature of thalassaemic ulcers being treated in a hyperbaric oxygen chamber.

\section{Conclusion}

Thalassaemia should be considered as a possible cause of leg ulceration in patients of Mediterranean origin. Venography can be used as a diagnostic tool to exclude venous ulceration and thus eliminate this potential misdiagnosis. Hyperbaric oxygen by way of a recompression chamber can successfully be used to treat thalassaemic ulceration.

\section{Acknowledgements}

The authors are grateful to Dr Angostiniotis for his $\overrightarrow{0}$ permission to publish the patient's 'family tree' and to $\vec{\overrightarrow{ }}$ the Director General Medical Services (RAF) for permission to publish the paper.

\section{REFERENCES}

1. Danes-Mend T K and Peachey R D G. Leg Ulcers in $\propto \vec{\omega}$ Thalassaemia (Haemoglobin $\mathrm{H}$ disease). Br J Dermatol 1978; 98:233-235.

2. Gimmon Z, Wexler $M R$ and Rachmilewitz $E$ e Juvenile Leg Ulceration in B Thalassaemia Major and Intermedia. Plast Reconstr Surg 1982; 69: 320-322.

3. Myers R A M, BAKer T and COWLey R A.Hyperbarie Medicine: State of the Art. Amer Surg 1979; 48:487-49요

4. KAPLAN E G et al. Superficial Ulcer Treatment Utilisir Hyperbaric Oxygen and Porcine Skin Grafts. J Fo ब̊ Surg 1978; 17:144-148.

5. PeACHey R D G. Leg Ulceration and Haemolytis Anaemia: An Hypothesis. Br J Dermatol 1978; 98 $245-248$.

6. FISCHER B H. Treatment of Ulcers on the Legs wi苚. Hyperbaric Oxygen. J Dermatol Surg 1975; 1:55-58.

7. HENG M C Y, PILgRim J P and BECK F W J. A simplified Hyperbaric Oxygen Technique for Leg Ulcers. Arch Dermatol 1984; 120:640-645.

8. OlejNiczak $\mathrm{S}$ and Zielinski A. Low Hyperbaric Therapy in Management of Leg Ulcers. Mich Med 1975; 74:707-712. 